\title{
Substratos alternativos para produção de repolho e beterraba em consórcio e monocultivo
}

\author{
Luiz A. de M. Costa ${ }^{1}$, Dercio C. Pereira ${ }^{2} \&$ Mônica S. S. de M. Costa $^{3}$
}

${ }^{1}$ Bolsista CNPq/RHAE. Cascavel, PR. E-mail: lmendo@ig.com.br

${ }^{2}$ UNIOESTE. Cascavel, PR. E-mail: dercioceri@gmail.com (Autor correspondente)

${ }^{3}$ UNIOESTE. Cascavel, PR. E-mail: mssmc@ig.com.br

\section{Palavras-chave:}

Beta vulgaris

Brassica oleracea

composto orgânico

pó de basalto

\section{R E S U M O}

Objetivou-se, com este trabalho, determinar o desempenho dos substratos alternativos no desenvolvimento radicular e na parte aérea da beterraba e do repolho, tal como no seu comportamento no campo em consórcio e monocultivo. Foram realizados dois experimentos em blocos casualizados cujos tratamentos foram: $\mathrm{T}_{0}$ (substrato Plantmax ${ }^{\otimes}$ ); $\mathrm{T}_{1}$ (100\% de composto); $\mathrm{T}_{2}$ (50\% de composto, $20 \%$ de areia, $20 \%$ de casca de arroz carbonizada e $10 \%$ de pó de basalto); $\mathrm{T}_{3}$ (45\% de composto, $20 \%$ de areia, $20 \%$ de casca de arroz carbonizada e $15 \%$ de pó de basalto); $\mathrm{T}_{4}(40 \%$ de composto, $5 \%$ de areia e $15 \%$ casca de arroz carbonizada e $20 \%$ de pó de basalto) e $\mathrm{T}_{5}$ (35\% de composto, $5 \%$ de areia e $15 \%$ de casca de arroz carbonizada e $25 \%$ de pó de basalto). O primeiro experimento foi em bandejas de 200 células; o segundo foi no campo em monocultivo e consociado com tratamentos constituídos pelos substratos utilizados em bandeja. No canteiro para o repolho os substratos em monocultivo e consorciado apresentaram acúmulos semelhantes de massa seca da cabeça; já para beterraba o diâmetro da raiz com o substrato comercial apresentou superioridade para o consórcio comparado ao monocultivo, enquanto para a produção de beterraba $\mathrm{e}$ repolho em sistema de monocultivo e consorciado podem ser recomendados os substratos alternativos.
Key words:

Beta vulgaris

Brassica oleracea

organic compost

basalt powder

\section{Alternative substrates for the production of cabbage and beetroot in consortium and monoculture systems}

\begin{abstract}
A B S T R A C T
The aim of this study was to assess the efficiency of alternative substrates for the development of the root system in the shoots of beetroot and cabbage seedlings as well as their behavior in field under monoculture and consortium systems. Two experiments were performed in randomized block design with the use of the following treatments: $\mathrm{T}_{0}$ (Plantmax ${ }^{\oplus}$ substrate); $\mathrm{T}_{1}\left(100 \%\right.$ of compost); $\mathrm{T}_{2}$ (50\% of compost, $20 \%$ of sand, $20 \%$ of carbonized rice hulls and $10 \%$ of basaltic dust); $\mathrm{T}_{3}$ ( $45 \%$ of compost, $20 \%$ of sand, $20 \%$ of carbonized rice hulls and $15 \%$ of basaltic dust); $\mathrm{T}_{4}$ ( $40 \%$ of compost, $5 \%$ of sand, $15 \%$ of carbonized rice hulls and $20 \%$ of basaltic dust) and $\mathrm{T}_{5}$ ( $35 \%$ of compost, $5 \%$ of sand and $15 \%$ of carbonized rice hulls and $25 \%$ of basaltic). The first experiment was performed in trays of 200 cells and the second one in the field under monoculture system and in consort with the treatments composed of the substrates used in the trays. For the cabbage production in the field, substrates used in consortium and in monoculture showed similar results regarding the accumulation of dry mass in the shoot of the plant. As for the the beetroot, the diameter of the roots with commercial substrate was greater under consortium system when compared to monoculture system. For the production of beetroot and cabbage in monoculture and consortium systems, alternative substrate can be recommended.
\end{abstract}

\section{INTRODUÇão}

A obtenção de mudas pela utilização de substratos é uma prática comum na produção de hortaliças, pois os produtores almejam plantas vigorosas e bem desenvolvidas. O substrato é um insumo importante devido à sua ampla utilização no cultivo de mudas (Freitas et al., 2013). De acordo com Medeiros et al. (2010) o substrato deve proporcionar eficiência na germinação e emergência de plântulas, além de fornecer suprimento adequado de nutrientes, oxigênio e eliminação do $\mathrm{CO}_{2}$. Para que isto seja conseguido o substrato deve ser provido de boas características físicas, químicas, biológicas e sanitárias para obtenção de mudas de qualidade (Santos et al., 2010; Lopes et al., 2012; Mesquita et al., 2012).

Para Steffen et al. (2010) a escolha do substrato é baseada em dois critérios: no custo de aquisição e na disponibilidade do material para produção. Desta forma, existe a possibilidade da utilização de substratos constituídos de subprodutos agrícolas de determinada região, que podem ser conseguidos facilmente, como casca de arroz, carvão, palha de café, esterco animal, além de subprodutos da agroindústria (Araújo Neto et al., 2009). 
Neste sentido se utilizaram, para a produção de mudas de repolho, sementes cultivadas em copinhos ou bandejas preenchidos com substratos até o desenvolvimento e estabelecimento das mudas. As mudas de repolho com 10 a $12 \mathrm{~cm}$ de altura ou com quatro a cinco folhas definitivas são transplantadas para o canteiro. Atualmente, trabalha-se com híbridos tolerantes ao calor permitindo o plantio em determinadas regiões durante todo o ano. Desta forma, a escolha da cultivar deve ser em função do clima local (Vidigal et al., 2007). Na cultura do repolho o acúmulo de massa seca aumenta até os 70 dias após o transplante com maiores acréscimos dos 40 aos 60 dias (Castoldi et al., 2009).

A beterraba é propagada por sementes; ela admite o plantio direto ou indireto em bandejas e posterior transplante em canteiros; a formação de mudas em bandeja possibilita melhor aproveitamento das sementes gastando-se de 5 a $6 \mathrm{~kg}$ de sementes por hectare. A beterraba apresenta crescimento inicial lento, tolera salinidade e as sementes possuem poucas reservas (Puiatti \& Finger, 2007). De acordo com Grangeiro et al. (2007), o acúmulo máximo de matéria seca na beterraba ocorre no período entre 50 e 60 dias após a semeadura.

Assim, repolho e beterraba podem ser cultivados em combinação, ou seja, em consórcio, pois colaboram no desenvolvimento mútuo. Em consórcio as plantas de ciclos ou portes distintos reduzem a competição com ervas espontâneas, promovem a liberação de substâncias no solo para solubilização e absorção de nutrientes inacessíveis a outros vegetais (Gliessman, 2009).

Para Oliveira et al. (2005), em meio às técnicas alternativas pode-se utilizar o consórcio de culturas em que, anteriormente, a modernização e a industrialização da agricultura eram comuns, sendo a exceção o monocultivo.

Para Rezende et al. (2006) o consórcio de culturas representa um sistema intermediário entre a monocultura e as condições de vegetação natural, onde habitam duas ou mais espécies em um mesmo local durante determinado período de tempo; contudo, para se obter resultados positivos de um sistema de cultivo em consórcio a escolha das espécies a serem utilizadas deverá ser criteriosa. De acordo com Teixeira et al. (2005), para que a população vegetal seja uniforme ou heterogênea as plantas são susceptíveis a várias interações. Geralmente, nos agroecossistemas interações entre os vegetais são observadas como as plantas companheiras que convivem nas mesmas áreas de forma mutualística (Gliessman, 2009); assim, a consorciação é empregada por pequenos agricultores devido aos poucos recursos disponíveis, pouca área de terra, pela mão-de-obra abundante para o manejo e por ser superior ao monocultivo em produção vegetal. $\mathrm{O}$ objetivo deste trabalho foi determinar o desempenho de substratos alternativos no desenvolvimento radicular e de parte aérea das espécies beterraba e repolho, tal como seu comportamento no campo, em sistema de consórcio e monocultivo.

\section{MAterial e Métodos}

O experimento foi conduzido na Fazenda Escola da Faculdade Assis Gurgacz (FAG), em Cascavel - Paraná. A área está situada a $2^{\circ} 46^{\prime} 483^{\prime \prime}$ de latitude sul, $72^{\circ} 39^{\prime} 117^{\prime \prime}$ de longitude oeste com altitude média de $700 \mathrm{~m}$. O solo classificado como Latossolo Vermelho Distroférrico típico (EMBRAPA, 2006); o clima, segundo a classificação de Köppen, se enquadra no tipo Cfa, com temperatura média anual de $19,5^{\circ} \mathrm{C}$ e precipitação média anual de $1.950 \mathrm{~mm}$ (IAPAR, 1994).

Foram realizados dois ensaios. O delineamento experimental no primeiro ensaio foi de blocos ao acaso em estufa modelo arco, com seis tratamentos e três repetições. Os tratamentos foram: $\mathrm{T}_{0}$ (substrato Plantmax $\left.{ }^{\circledast}\right) ; \mathrm{T}_{1}$ (100\% de composto); $\mathrm{T}_{2}(50 \% \mathrm{de}$ composto, $20 \%$ de areia, $20 \%$ de casca de arroz carbonizada e $10 \%$ de pó de basalto); $\mathrm{T}_{3}$ (45\% de composto, $20 \%$ de areia, $20 \%$ de casca de arroz carbonizada e $15 \%$ de pó de basalto); $\mathrm{T}_{4}(40 \%$ de composto, $5 \%$ de areia e $15 \%$ casca de arroz carbonizada e $20 \%$ de pó de basalto) e $\mathrm{T}_{5}$ ( $35 \%$ de composto, $5 \%$ de areia e $15 \%$ de casca de arroz carbonizada e $25 \%$ de pó de basalto). O pó de basalto é derivado da rocha que origina os solos da Região Oeste do Paraná. O composto foi obtido a partir de restos vegetais e esterco bovino. A análise química do composto é apresentada na Tabela 1.

Os substratos foram obtidos variando as porcentagens em peso de composto, areia, casca de arroz carbonizada e pó de basalto. $\mathrm{O}$ composto e a areia (média: $>0,18 \mathrm{~mm}$ e $<0,42$ $\mathrm{mm}$ ) foram passados em peneira de madeira e tela galvanizada com 6 malhas quadradas por polegada linear (abertura 3,67 $\mathrm{mm})$ e bitola dos fios $24(0,55 \mathrm{~mm})$, segundo a classificação de Birmingham Wire Gauge (BWG) e $60 \mathrm{~cm}$ de diâmetro; em seguida, todos os componentes dos substratos foram misturados e homogeneizados. Os substratos foram distribuídos sobre bandejas de polietileno expandido e se mantendo a uniformidade de preenchimento das células.

A semeadura das sementes de beterraba e do repolho foram realizadas manualmente. Foram utilizadas dezoito bandejas com 200 células para o plantio. A semeadura de cada espécie foi realizada em 100 células das bandejas, totalizando 200 mudas por bandeja, perfazendo 1.800 mudas por espécie, no total de 3.600 mudas. As bandejas foram dispostas no sentido norte-sul no interior da estufa e realizado o rodízio de quatro em quatro dias.

Durante o período experimental (26/10/2007 a 20/11/2007) foram realizadas as seguintes avaliações: comprimento da parte aérea das plântulas (CPA) e comprimento de raiz (CR). A temperatura máxima, mínima e umidade relativa do ar durante o período experimental é apresentada na Figura 1.

O segundo ensaio foi realizado no campo, em 20/11/2007, com quatro blocos casualizados e seis tratamentos em esquema fatorial $(2 \times 6$ ), constituído de dois sistemas de cultivo (consórcio

Tabela 1. Composição química média do composto de resíduos vegetal e animal

\begin{tabular}{|c|c|c|c|c|c|c|c|c|c|c|}
\hline \multirow{3}{*}{ Composto } & \multirow{3}{*}{$\begin{array}{c}\mathbf{C} \\
\mathbf{g ~ d \mathbf { d m } ^ { - 3 }} \\
122,50\end{array}$} & \multirow{2}{*}{$\mathrm{pH}$} & \multirow{2}{*}{$\begin{array}{c}P \\
\mathrm{mg} \mathrm{dm^{-3 }}\end{array}$} & $K$ & Ca & $\mathrm{Mg}$ & $\mathrm{Zn}$ & $\mathrm{Cu}$ & $\mathrm{Fe}$ & Mn \\
\hline & & & & \multicolumn{3}{|c|}{$\mathrm{cmol}_{\mathrm{c}} \mathrm{dm}^{-3}$} & \multicolumn{4}{|c|}{$\mathrm{mg} \mathrm{kg}^{-1}$} \\
\hline & & 6,20 & 646,10 & 1,14 & 13,00 & 6,47 & 58,00 & 2,30 & 1,00 & 264,00 \\
\hline
\end{tabular}




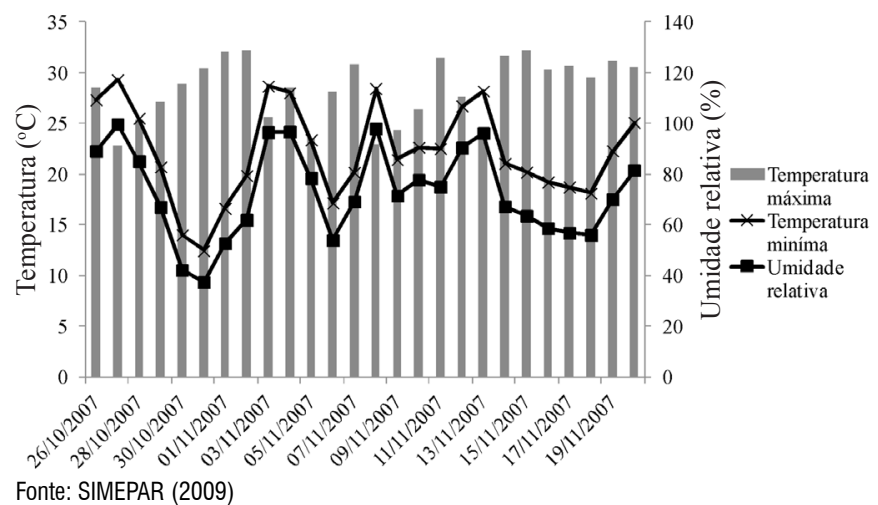

Figura 1. Temperatura máxima e mínima $\left({ }^{\circ} \mathrm{C}\right)$, e umidade relativa do ar (\%) durante o período de outubro a novembro de 2007

e monocultivo) e os seis substratos utilizados em bandejas submetidos ao transplante em canteiro, totalizando 24 parcelas. A temperatura e a precipitação durante o período experimental no campo são apresentadas na Figura 2.

Os tratamentos foram constituídos pelos substratos utilizados nas bandejas. Os canteiros de 1,20 x 1,00 m com 1,20 $\mathrm{m}^{2}$ foram as parcelas apresentando quatro linhas longitudinais de plantio com espaçamento $0,30 \times 0,60 \mathrm{~m}$. Utilizou-se uma muda de repolho por cova totalizando oito plantas por parcela. Para a beterraba em monocultivo utilizaram-se 18 plantas por parcela distribuídas em cinco linhas com espaçamento de 0,20 $\mathrm{x} 0,20 \mathrm{~m}$. No consórcio a parcela foi constituída de 12 plantas de repolho com espaçamento de $0,30 \times 0,33 \mathrm{~m}$ e beterraba com seis plantas com espaçamento de 0,50 x 0,40 m. Na Figura 3 é apresentado o croqui das parcelas do repolho e da beterraba em monocultivo e consórcio.

A confecção dos canteiros foi realizada com enxada rotativa leve (modelo RL 125), antecedendo o plantio das mudas no local definitivo; na Tabela 2 é apresentada a análise química do solo por ocasião do transplante das mudas.

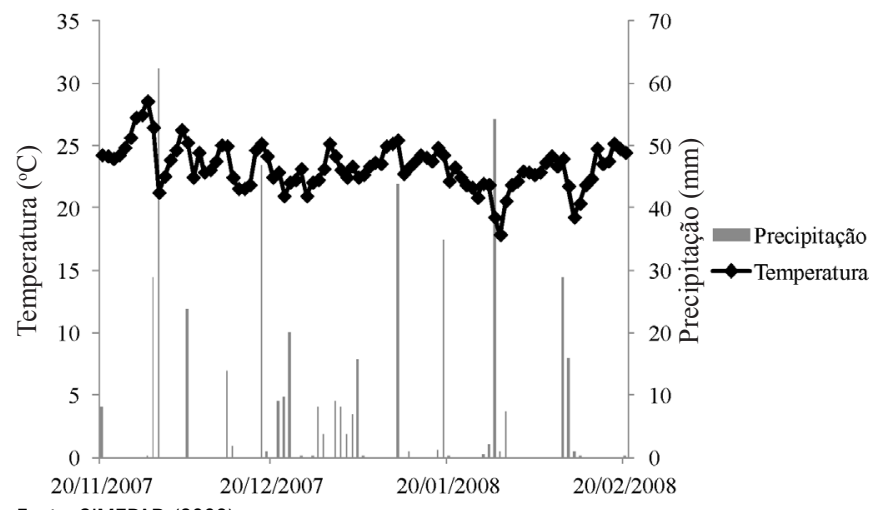

Fonte: SIMEPAR (2009)

Figura 2. Temperatura e precipitação durante o período de novembro de 2007 a fevereiro de 2008

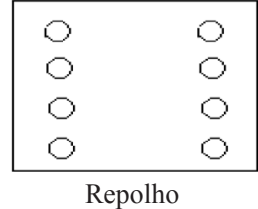

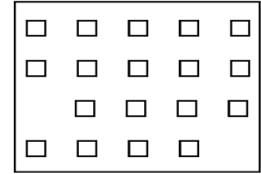

Beterraba

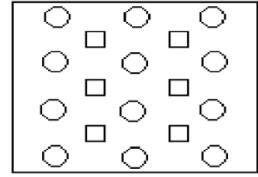

Consórcio
Figura 3. Croqui das parcelas para repolho e beterraba em monocultivo e consórcio

A adubação dos canteiros foi realizada com distribuição manual na superfície, de $3 \mathrm{~kg}$ de composto orgânico por metro quadrado. O composto foi destorroado e passado em peneira de malha seis para melhor homogeneização. No momento em que as mudas atingiram o ponto de transplante, aos 25 dias após a emergência, estas foram levadas para os canteiros; as plantas foram irrigadas diariamente, duas vezes ao dia, por aspersão.

Para as avaliações foram consideradas as três linhas centrais. As plantas foram colhidas quando as cabeças alcançaram compacidade (firmeza a compressão manual). As plantas coletadas foram lavadas e separadas em raiz, caule e parte aérea. No final do período experimental determinou-se o diâmetro da cabeça do repolho (DC) e da raiz da beterraba (DR), com auxílio de paquímetro digital.

Utilizando-se balança analítica foram determinadas, para o repolho, as massas fresca e seca da raiz (MFR, MSR), massa fresca e seca do caule (MFC, MSC) e as massas fresca e seca da cabeça (MFCA, MSCA). Para a beterraba determinou-se as massas fresca e seca da raiz (MFR, MSR) e as massas fresca e seca das folhas (MFF, MSF). As plantas foram secas em estufa com circulação de ar forçada a $65^{\circ} \mathrm{C}$, até peso constante; os resultados obtidos foram submetidos à análise de variância e as diferenças entre as médias testadas pelo teste de LSD a 5\% de probabilidade utilizando-se o software estatístico SISVAR versão 4.3 (Ferreira, 2000).

\section{Resultados e Discussão}

Na Tabela 3 são apresentadas as médias de altura das plântulas e o comprimento das raízes de beterraba e repolho em cada tratamento aos 30 dias após a semeadura.

A presença de composto orgânico na composição dos substratos alternativos possibilitou maior crescimento da parte aérea da beterraba em todos os tratamentos, com exceção de $\mathrm{T}_{0}$. É provável que o substrato alternativo, por ter em sua constituição pó de basalto, tenha possibilitado maior CPA devido à disponibilidade de nutrientes, proporcionado pela associação com o composto que, provavelmente, tenha propiciado uma mineralização mais rápida dos nutrientes (Leal et al., 2011).

Nota-se que o CPA seguiu a composição em nutrientes dos substratos alcançando altura máxima em $\mathrm{T}_{1}$. Este resultado foi superior ao obtido por Leal et al. (2007) de 10,33 cm, aos 33 dias após a semeadura utilizando composto com $66 \%$ de Crotalaria juncea $+33 \%$ de Napier.

Tabela 2. Análise química inicial do solo

\begin{tabular}{|c|c|c|c|c|c|c|c|c|}
\hline \multirow{2}{*}{$\begin{array}{l}\text { Profundidade } \\
\text { (cm) }\end{array}$} & \multirow{2}{*}{$\begin{array}{c}\mathrm{pH} \\
\mathrm{CaCl}_{2}\end{array}$} & $\mathrm{Ca}$ & $\mathrm{Mg}$ & $K$ & CTC & \multirow{2}{*}{$\begin{array}{c}\mathrm{MO} \\
\mathrm{g} \mathrm{dm}^{-3}\end{array}$} & \multirow{2}{*}{$\begin{array}{c}P \\
\mathrm{mg} \mathrm{dm}^{-3}\end{array}$} & \multirow{3}{*}{$\begin{array}{c}\mathbf{V} \\
\%\end{array}$} \\
\hline & & \multicolumn{4}{|c|}{$\mathrm{cmol}_{\mathrm{c}} \mathrm{dm}^{-3}$} & & & \\
\hline $0-10$ & 5,50 & 8,84 & 2,59 & 0,84 & 16,88 & 49,64 & 40,42 & \\
\hline
\end{tabular}


Tabela 3. Valores médios do comprimento da parte aérea e comprimento de raiz em bandejas com beterraba e repolho sob estufa 30 dias após o plantio

\begin{tabular}{|c|c|c|c|c|}
\hline \multirow{3}{*}{ Tratamentos } & \multicolumn{2}{|c|}{ Beterraba } & \multicolumn{2}{|c|}{ Repolho } \\
\hline & CPA & CR & CPA & CR \\
\hline & \multicolumn{4}{|c|}{ (cm) } \\
\hline $\mathrm{T}_{0}$ & $3,26 \mathrm{~b}$ & $4,53 \mathrm{~b}$ & $2,93 \mathrm{~d}$ & $3,80 \mathrm{~b}$ \\
\hline $\mathrm{T}_{1}$ & $11,30 \mathrm{a}$ & $7,53 a b$ & $11,20 \mathrm{a}$ & $6,33 \mathrm{a}$ \\
\hline $\mathrm{T}_{2}$ & $10,16 a$ & $8,50 \mathrm{a}$ & 6,36 bc & $7,86 \mathrm{a}$ \\
\hline $\mathrm{T}_{3}$ & $9,76 \mathrm{a}$ & $7,40 a b$ & $8,53 \mathrm{~b}$ & $7,36 \mathrm{a}$ \\
\hline $\mathrm{T}_{4}$ & $8,40 a$ & $8,73 \mathrm{a}$ & $8,10 \mathrm{~b}$ & $8,16 \mathrm{a}$ \\
\hline $\mathrm{T}_{5}$ & $7,76 \mathrm{a}$ & $6,43 a b$ & $5,63 \mathrm{c}$ & $8,56 \mathrm{a}$ \\
\hline DMS & 4,49 & 3,73 & 2,37 & 2,36 \\
\hline CV\% & 19,42 & 18,95 & 12,14 & 12,28 \\
\hline
\end{tabular}

CPA - comprimento da parte aérea, CR - comprimento da raiz, DMS - diferença mínima significativa; CV = Coeficiente de variação; Médias, seguidas de mesma letra, dentro de cada parâmetro, não diferem entre si, pelo teste LSD, a 0,05 de probabilidade; $T_{0}$ (substrato Plantmax $\left.{ }^{\circledR}\right) ; T_{1}$ (100\% de composto); $T_{2}$ (50\% de composto, $20 \%$ de areia, $20 \%$ de casca de arroz carbonizada e $10 \%$ de pó de basalto); $\mathrm{T}_{3}$ (45\% de composto, $20 \%$ de areia, $20 \%$ de casca de arroz carbonizada e $15 \%$ de pó de basalto); $T_{4}$ (40\% de composto, $5 \%$ de areia e $15 \%$ casca de arroz carbonizada e $20 \%$ de pó de basalto) e $\mathrm{T}_{5}$ (35\% de composto, $5 \%$ de areia e $15 \%$ de casca de arroz carbonizada e $25 \%$ de pó de basalto)

As plântulas de beterraba que cresceram nos tratamentos $\mathrm{T}_{2}$ e $\mathrm{T}_{4}$ apresentaram CR estatisticamente superior ao $\mathrm{T}_{0}$. Os substratos com casca de arroz carbonizada e areia possibilitam melhor drenagem da água retida nos macroporos criando espaço de ar e contribuindo com a respiração das raízes e atividade dos micro-organismos (Pagliarini et al., 2012).

Para as plântulas de repolho houve crescimento significativo do CPA em $\mathrm{T}_{1}$ superando os demais tratamentos. O tratamento $\mathrm{T}_{1}$ apresentou diferença de $8,27 \mathrm{~cm}$ no $\mathrm{CPA}$ em relação a $\mathrm{T}_{0}$. Isso indica que o composto forneceu condições físicas, químicas e biológicas para o desenvolvimento da parte aérea. Lima et al. (2007) trabalhando com três fontes de matéria orgânica: esterco bovino curtido, casca de amendoim e casca de mamona como subtratos, citam que casca de amendoim e casca de mamona possuem bom conteúdo de nutrientes, mas como não passaram por processo de decomposição os nutrientes não foram fornecidos às plantas.

Para a característica CR do repolho os substratos alternativos proporcionaram crescimento de raiz significativamente superior ao $\mathrm{T}_{0}$. É possível que a raiz de repolho tenha encontrado, nesses substratos, condições químicas favoráveis ao crescimento radicular (Pereira et al., 2012).

$\mathrm{Na}$ Tabela 4 são apresentados os resultados para as características diâmetro da cabeça (DC), massa fresca da raiz
(MFR), massa seca da raiz (MSR), massa fresca do caule (MFC), massa seca do caule (MSC), massa fresca da cabeça (MFCA) e massa seca da cabeça para o cultivo do repolho em monocultivo e consórcio.

No canteiro os substratos orgânicos não apresentaram resultados significativos e interações com os sistemas de cultivo consorciado e monocultivo. Isso indica que as mudas cultivadas com os substratos respondem de modo semelhante após o transplante, pois as exigências e disponibilidade de nutrientes, as condições físicas que determinaram o crescimento e o desenvolvimento foram semelhantes no período em que permaneceram no solo (Oliveira et al., 2010).

De acordo com os resultados da análise estatística dos sistemas de plantio, observaram-se diferenças significativas entre o cultivo de repolho consorciado e o monocultivo. O sistema de monocultivo proporcionou maior DC e acúmulo de MFR, MSR, MFC, MSC e MFCA. Tal fato pode ser relacionado ao espaçamento para crescimento e desenvolvimento das plantas visto que a competição por fatores abióticos (luminosidade, nutrientes, água) é menor em função da área ocupada pelo vegetal (Tolentino Júnior et al., 2002).

Por outro lado, constatou-se, em consórcio, menor DC e acúmulo de massa seca nas partes analisadas; entretanto, para a MSCA o resultado foi semelhante dentre os sistemas de cultivo; isso possivelmente resultou pela distribuição equilibrada da matéria seca entre os sistemas de cultivo no órgão de interesse no vegetal. Diferente dos demais órgãos que apresentaram distribuição não homogênea de matéria seca, sobretudo em partes vegetais frescas (Benincasa, 2003). Desse modo, os sistemas vegetais são capazes de se autoregularem, baseandose na capacidade de adaptação do organismo individual e das populações (Paula et al., 2009).

$\mathrm{Na}$ Tabela 5 são apresentadas as médias da massa fresca da raiz (MFR), massa seca da raiz (MSR), massa seca da folha (MSF) da beterraba em função do monocultivo e consórcio com transplante em canteiro.

As MFR, MSR e MSF da beterraba não diferiram nos sistemas de cultivo e entre os tratamentos, indicando que tais características não foram afetadas pelas competições intra e interespecífica das plantas. Provavelmente, em monocultivo ou consórcio foram atendidas as necessidades nutricionais e os espaços explorados pelas raízes e área foliar, condições que favoreceram a regulação do meio. Desse modo, em avaliação

Tabela 4. Valores médios do diâmetro da cabeça, massa fresca e seca da raiz, massa fresca e seca do caule, massa fresca e seca da cabeça do repolho em função do monocultivo e consórcio com transplante em canteiro

\begin{tabular}{lccccccc}
\hline Sistemas & DC & MFR & MSR & MFC & MSC & MFCA & MSCA \\
\cline { 2 - 7 } de cultivo & $(\mathbf{m m})$ & & & & $\mathbf{( g )}$ & & \\
Monocultivo & $121,23 \mathrm{a}$ & $24,89 \mathrm{a}$ & $9,19 \mathrm{a}$ & $73,30 \mathrm{a}$ & $6,60 \mathrm{a}$ & $909,82 \mathrm{a}$ \\
Consórcio & $98,90 \mathrm{~b}$ & $19,81 \mathrm{~b}$ & $5,50 \mathrm{~b}$ & $26,05 \mathrm{~b}$ & $5,18 \mathrm{~b}$ & $656,19 \mathrm{~b}$ & $55,74 \mathrm{a}$ \\
DMS & 10,67 & 3,62 & 1,23 & 14,75 & 0,86 & 146,41 \\
CV\% & 16,51 & 27,58 & 28,45 & 50,55 & 24,73 & 31,84 & 34,35 \\
\hline
\end{tabular}

Médias seguidas pela mesma letra minúscula nas colunas, não diferem estatisticamente entre si a 0,05 de probabilidade; $T_{0}$ (substrato Plantmax ${ }$ ); $T_{1}$ (100\% de composto); $T_{2}$ ( $50 \%$ de composto, $20 \%$ de areia, $20 \%$ de casca de arroz carbonizada e $10 \%$ de pó de basalto); $T_{3}$ (45\% de composto, $20 \%$ de areia, $20 \%$ de casca de arroz carbonizada e $15 \%$ de pó de basalto); $\mathrm{T}_{4}$ (40\% de composto, $5 \%$ de areia e $15 \%$ casca de arroz carbonizada e $20 \%$ de pó de basalto) e $\mathrm{T}_{5}$ (35\% de composto, $5 \%$ de areia e $15 \%$ de casca de arroz carbonizada e $25 \%$ de pó de basalto); DC - diâmetro da cabeça, MFR, MSR - massa fresca e seca da raiz, MFC, MSC - massa fresca e seca do caule, MFCA, MSCA - massa fresca e seca da cabeça do repolho; DMS - Diferença mínima significativa, CV - Coeficiente de variação 
Tabela 5. Valores médios da massa fresca da raiz, massa seca da raiz, massa seca da folha da beterraba em função do monocultivo e consorcio com transplante em canteiro

\begin{tabular}{lccr}
\hline & MFR & MSR & MSF \\
\cline { 2 - 4 } Sistemas de cultivo & \multicolumn{3}{c}{$\mathbf{( g )}$} \\
Monocultiv0 & $157,92 \mathrm{a}$ & $13,97 \mathrm{a}$ & $5,71 \mathrm{a}$ \\
Consórcio & $116,05 \mathrm{a}$ & $12,61 \mathrm{a}$ & $4,30 \mathrm{a}$ \\
DMS & 47,42 & 3,59 & 1,53 \\
CV \% & 58,94 & 45,99 & 52,18 \\
\hline Tratamentos & & & \\
$\mathrm{T}_{0}$ & $116,13 \mathrm{a}$ & $11,84 \mathrm{a}$ & $3,11 \mathrm{a}$ \\
$\mathrm{T}_{1}$ & $175,27 \mathrm{a}$ & $17,78 \mathrm{a}$ & $5,73 \mathrm{a}$ \\
$\mathrm{T}_{2}$ & $112,22 \mathrm{a}$ & $11,34 \mathrm{a}$ & $5,05 \mathrm{a}$ \\
$\mathrm{T}_{3}$ & $135,39 \mathrm{a}$ & $10,22 \mathrm{a}$ & $4,15 \mathrm{a}$ \\
$\mathrm{T}_{4}$ & $158,57 \mathrm{a}$ & $13,76 \mathrm{a}$ & $5,58 \mathrm{a}$ \\
$\mathrm{T}_{5}$ & $124,33 \mathrm{a}$ & $14,80 \mathrm{a}$ & $6,39 \mathrm{a}$ \\
DMS & 82,13 & 6,22 & 2,66 \\
CV \% & 58,94 & 45,99 & 52,18 \\
\hline
\end{tabular}

Médias seguidas pela mesma letra minúscula nas colunas, não diferem estatisticamente entre si a 0,05 de probabilidade; $T_{0}$ (substrato Plantmax®); $T_{1}\left(100 \%\right.$ de composto); $T_{2}$ ( $50 \%$ de composto, $20 \%$ de areia, $20 \%$ de casca de arroz carbonizada e $10 \%$ de pó de basalto); $\mathrm{T}_{3}$ ( $45 \%$ de composto, $20 \%$ de areia, $20 \%$ de casca de arroz carbonizada e $15 \%$ de pó de basalto); $\mathrm{T}_{4}$ ( $40 \%$ de composto, $5 \%$ de areia e $15 \%$ casca de arroz carbonizada e $20 \%$ de pó de basalto) e $\mathrm{T}_{5}$ (35\% de composto, $5 \%$ de areia e $15 \%$ de casca de arroz carbonizada e $25 \%$ de pó de basalto); MFR - massa fresca da raiz, MSR - massa seca da raiz, MSF - massa seca da folha da beterraba; DMS - Diferença mínima significativa, CV - Coeficiente de variação

agroeconômica das culturas da beterraba e do coentro conforme a época ( 0,7 e 14 dias) do estabelecimento do consórcio, não foram observadas diferenças significativas entre os sistemas de cultivo (monocultivo e consórcio), época de semeaduras do coentro, altura de plantas, massa seca da parte aérea e produtividade da beterraba (Grangeiro et al., 2011).

Na Tabela 6 são apresentadas as médias do diâmetro da raiz (DR) e massa fresca da folha (MFF) da beterraba em função do sistema de cultivo da beterraba em canteiro.

A interação entre sistemas de cultivo e os tratamentos para as variáveis DR e MFF nas plantas de beterraba foram significativos; para a característica DR observou-se, na analise dos sistemas, no monocultivo que os substratos à base de composto apresentaram

Tabela 6. Valores médios do diâmetro da raiz, massa fresca das folhas da beterraba em função do sistema de monocultivo e consórcio com transplante em canteiro

\begin{tabular}{|c|c|c|c|c|}
\hline \multirow{3}{*}{ Tratamentos } & \multicolumn{4}{|c|}{ Sistemas } \\
\hline & Monocultivo & Consórcio & Monocultivo & Consórcio \\
\hline & \multicolumn{2}{|c|}{ DR $(\mathrm{mm})$} & \multicolumn{2}{|c|}{ MFF $(g)$} \\
\hline $\mathrm{T}_{0}$ & $54,43 \mathrm{aB}$ & $96,70 \mathrm{aA}$ & 11,57 aA & $23,36 \mathrm{bA}$ \\
\hline $\mathrm{T}_{1}$ & $66,90 \mathrm{aA}$ & $65,18 \mathrm{bA}$ & $25,28 \mathrm{aB}$ & 79,16 aA \\
\hline $\mathrm{T}_{2}$ & $60,57 \mathrm{aA}$ & $54,98 \mathrm{bA}$ & $16,98 \mathrm{aA}$ & $10,10 \mathrm{bA}$ \\
\hline $\mathrm{T}_{3}$ & 70,30 aA & $54,03 \mathrm{bA}$ & $24,63 \mathrm{aA}$ & $10,48 \mathrm{bA}$ \\
\hline $\mathrm{T}_{4}$ & $66,96 \mathrm{aA}$ & $68,47 \mathrm{bA}$ & $33,81 \mathrm{aA}$ & $28,49 \mathrm{bA}$ \\
\hline $\mathrm{T}_{5}$ & $68,00 \mathrm{aA}$ & $67,72 \mathrm{bA}$ & $27,65 \mathrm{aA}$ & $16,43 \mathrm{bA}$ \\
\hline DMS & 20,76 & 20,76 & 22,70 & 22,70 \\
\hline CV \% & 21,81 & 21,81 & 61,48 & 61,48 \\
\hline
\end{tabular}

Médias seguidas pela mesma letra, minúscula nas colunas e maiúscula nas linhas, não diferem estatisticamente entre si a 0,05 de probabilidade; $T_{0}$ (substrato Plantmax $\left.®\right) ; T_{1}$ (100\% de composto); $T_{2}$ (50\% de composto, $20 \%$ de areia, $20 \%$ de casca de arroz carbonizada e $10 \%$ de pó de basalto); $T_{3}$ (45\% de composto, $20 \%$ de areia, $20 \%$ de casca de arroz carbonizada e $15 \%$ de pó de basalto); T (40\% de composto, $5 \%$ de areia e $15 \%$ casca de arroz carbonizada e $20 \%$ de pó de basalto) e $\mathrm{T}_{5}$ (35\% de composto, $5 \%$ de areia e $15 \%$ de casca de arroz carbonizada e $25 \%$ de pó de basalto); DR - diâmetro da raiz, MFF - massa fresca das folhas da beterraba; DMS - Diferença mínima significativa, CV - Coeficiente de variação diâmetros semelhantes comparados ao consorciado, porém o substrato $\mathrm{T}_{0}$ em consórcio demonstrou comportamento superior em relação ao monocultivo. Resultados inferiores obtidos por Tolentino Júnior et al. (2002), em experimento com mandioquinha-salsa consorciada com alface e beterraba, no qual o diâmetro da beterraba em monocultivo foi de 4,71 $\mathrm{cm}$, maior que o das raízes em consórcio, que foi de $3,57 \mathrm{~cm}$.

Ainda com relação ao DR entre os substratos $\mathrm{T}_{1}, \mathrm{~T}_{2}, \mathrm{~T}_{3}, \mathrm{~T}_{4} \mathrm{e}$ $\mathrm{T}_{5}$ em monocultivo e consórcio, houve crescimento similar no sentido radial das raízes de beterraba, enquanto $\mathrm{T}_{0}$ evidenciou menor crescimento em monocultivo comparado ao consórcio. No caso dos substratos à base de composto no monocultivo houve competição intraespecífica das plantas que resultou em maior ocupação da área para exploração radicular. Em relação ao substrato $\mathrm{T}_{0}$, como as plantas apresentaram-se com menor CR (Tabela 3) por ocasião do transplante ocorreu uma compensação com crescimento radicular em profundidade para absorção de água e nutrientes (Gliessman, 2009).

Em relação à característica MFF entre os sistemas de cultivo, os substratos $\mathrm{T}_{0}, \mathrm{~T}_{2}, \mathrm{~T}_{3}, \mathrm{~T}_{4}$ e $\mathrm{T}_{5}$, utilizados no monocultivo demonstraram comportamento similar ao consórcio, enquanto $\mathrm{T}_{1}$ apresentou superioridade no sistema consorciado em relação ao monocultivo. Entre os substratos, no sistema de monocultivo, foi observado, para a MFF, desenvolvimento semelhante. No caso do sistema consorciado o substrato $\mathrm{T}_{1}$ mostrou resultado superior aos demais tratamentos, provavelmente pela capacidade do composto em fornecer nutrientes. Além disto, o maior ganho de MFF de beterraba foi obtido com as plantas consorciadas com mudas oriundas de $\mathrm{T}_{1}$, provavelmente por haver menos luz disponível, o que induziu as plantas a recorrerem a alguns mecanismos fisiológicos para se adaptarem à competição, dentre eles o aumento da altura. Isto visa expor a superfície da folha para maior interceptação e absorção de luz. Salvador et al. (2004) observaram que, devido à altura das plantas de cebolinha em consórcio apresentaram altura média de 9,8 cm acima das cultivadas em monocultivo, evidenciando a concorrência por luz, causando estiolamento.

\section{Conclusões}

1. O substrato composto, em bandeja, para o repolho aumenta o comprimento da parte aérea. O comprimento de raiz aumenta com os substratos: $40 \%$ de composto, $5 \%$ de areia, 15\% de casca de arroz carbonizada, 20\% de pó de basalto, e $35 \%$ de composto, $5 \%$ de areia, $15 \%$ de casca de arroz carbonizada, $25 \%$ de pó de basalto para beterraba e repolho, respectivamente.

2. As características fitométricas do repolho em monocultivo, para todos os substratos, foram superiores ao sistema consorciado. Os substratos no sistema de monocultivo e consorciado apresentam acúmulos semelhantes de massa seca da cabeça.

3. As características da beterraba: massa fresca e seca da raiz, e massa seca das folhas no monocultivo e consórcio foram 
semelhantes. No consórcio, o substrato comercial apresenta melhor diâmetro de raiz. O substrato composto em consórcio apresenta melhor massa fresca das folhas. Para produção de beterraba e repolho em sistema de monocultivo e consorciado podem ser recomendados todos os substratos alternativos.

\section{Literatura Citada}

Araújo Neto, S. E.; Azevedo, J. M. A.; Galvão, R. O.; Oliveira, E. B. L.; Ferreira, R. L. F. Produção de muda orgânica de pimentão com diferentes substratos. Ciência Rural, v.39, p.1408-1413, 2009.

Benincasa, M. M. P. Análise de crescimento de plantas (noções básicas). Jaboticabal: FUNEP, 2003. 41p.

Castoldi, R.; Charlo, H. C. O.; Vargas, P. F.; Braz, L. T. Crescimento, acúmulo de nutrientes e produtividade da cultura da couve-flor. Horticultura Brasileira, v.27, p.438446, 2009.

EMBRAPA - Empresa Brasileira de Pesquisa Agropecuária. Centro Nacional de Pesquisa de Solos. Sistema brasileiro de classificação de solos. 2.ed. Rio de Janeiro: Embrapa Solos, 2006. 306p.

Ferreira, D. F. Manual do sistema Sisvar para análises estatísticas. Lavras: UFLA, 2000. 66p.

Freitas, G. A.; Silva, R. R.; Barros, H. B.; Melo, A. V.; Abrahão, W. A. P. Produção de mudas de alface em função de diferentes combinações de substratos. Revista Ciência Agronômica, v.44, p.159-166, 2013.

Gliessman, S. R. Agroecologia: Processos ecológicos em agricultura sustentável. 4.ed., Porto Alegre: UFRGS, 2009. $658 \mathrm{p}$.

Grangeiro, L. C.; Negreiros, M. Z.; Souza, B. S.; Azevedo, P. E.; Oliveira, S. L.; Medeiros, M. A. Acúmulo e exportação de nutrientes em beterraba. Ciência e Agrotecnologia, v.31, p.267-273, 2007.

Grangeiro, L. C.; Santos, A. P.; Freitas, F. C. L.; Simão, L. M. C.; Bezerra Neto, F. Avaliação agroeconômica das culturas da beterraba e coentro em função da época de estabelecimento do consórcio. Revista Ciência Agronômica, v.42, p.242-248, 2011.

IAPAR - Instituto Agronômico do Paraná. Cartas climáticas do estado do Paraná. Londrina: IAPAR, 1994. 49p.

Leal, M. A. A.; Guerra, J. G. M.; Peixoto, R. T. G.; Almeida, D. L. Utilização de compostos orgânicos como substratos na produção de mudas de hortaliças. Horticultura Brasileira, v.25, p.392-395, 2007.

Leal, P. A. M. ; Costa, E.; Schiavo, J. A.; Pegorare, A. B. Seedling formation and field production of beetroot and lettuce in Aquidauana, Mato Grosso do Sul, Brazil. Horticultura Brasileira v.29, p.465-471, 2011.

Lima, R. L. S.; Severino, L. S.; Silva, M. I. L.; Beltrão, N. E. de M. Fontes e doses de matéria orgânica na composição do substrato para produção de muda de mamoneira. Revista Brasileira de Oleaginosas e Fibrosas, v.11, p.77-83, 2007.
Lopes, J. C.; Mauri, J.; Ferreira, A.; Alexandre, R. S.; Freitas, A. R. Broccoli production depending on the seed production system and organic and mineral fertilizer. Horticultura Brasileira, v.30, p.143-150, 2012.

Medeiros, A. S.; Silva, E.G.; Luison, E. A.; Andreani Júnior, R.; Andreani, D. I. K. Utilização de compostos orgânicos para uso como substratos na produção de mudas de alface. Revista Agrarian, v.3, p.261-266, 2010.

Mesquita, E. F.; Chaves, L. H. G.; Freitas, B. V.; Silva, G. A.; Sousa, M. V. R.; Andrade, R. Produção de mudas de mamoeiro em função de substratos contendo esterco bovino e volumes de recipientes. Revista Brasileira de Ciências Agrárias, v.7, p.58-65, 2012.

Oliveira, E. Q.; Souza, R. J.; Cruz, M. C. M.; Marques, V. B.; França, A. C. Produtividade de alface e rúcula, em sistema consorciado, sob adubação orgânica e mineral. Horticultura Brasileira, v.28, p.36-40, 2010.

Oliveira, F. L.; Ribas, R. G. T.; Junqueira, R. M.; Padovan, M. P.; Guerra, J. G. M.; Almeida, D. L.; Ribeiro, R. L. D. Desempenho do consórcio entre repolho e rabanete com pré-cultivo de crotalária, sob manejo orgânico. Horticultura Brasileira, v.23, p.184-188, 2005.

Pagliarini, M. K.; Castilho, R. M. M.; Alves, M. C. Caracterização físico-química de misturas de componentes de substrato com resíduo de celulose para fins de produção de mudas. Revista Brasileira de Agroecologia, v.7, p.160-169, 2012.

Paula, P. D.; Guerra, J. G. M.; Ribeiro, R. L. D.; Cesar, M. N. Z.; Guedes, R. E.; Polidoro, J. C. Viabilidade agronômica de consórcios entre cebola e alface no sistema orgânico de produção. Horticultura Brasileira, v.27, p.202-206, 2009.

Pereira, D. C.; Grutzmacher, P.; Bernardi, F. H.; Mallmann, L. S.; Costa, L. A. M.; Costa, M. S. S. M. Produção de mudas de almeirão e cultivo no campo, em sistema agroecológico. Revista Brasileira de Engenharia Agrícola e Ambiental, v.16, p.1100-1106, 2012.

Puiatti, M.; Finger, F. L. In: Paula Júnior, T. J.; Venzon, M. (Ed.). 101 culturas: manual de tecnologias agrícolas. Belo Horizonte: EPAMIG, 2007. p.155-160.

Rezende, B. L. A.; Cecílio Filho, A. B.; Feltrim, A. L.; Costa, C. C.; Barbosa, J. C. Viabilidade da consorciação de pimentão com repolho, rúcula, alface e rabanete. Horticultura Brasileira. v.24, p.36-41, 2006.

Salvador, D. J.; Zárate, N. A. H.; Vieira, M. C. Produção e renda bruta de cebolinha e de almeirão, em cultivo solteiro e consorciado. Acta Scientiarum. Agronomy, v.26, p.491496, 2004.

Santos, M. R.; Sediyama, M. A. N.; Salgado, L. T.; Vidigal, S. M.; Reigado, F. R. Produção de mudas de pimentão em substratos à base de vermicomposto. Bioscience Journal, v.26, p.572-578, 2010.

SIMEPAR - Sistema Meteorológico do Paraná (2009) Histórico. $<$ http//www.simepar.br/>. 21 Jan. 2009. 
Steffen, G. P. K.; Antoniolli, Z. I.; Steffen, R. B.; Machado, R. G. Casca de arroz e esterco bovino como substratos para a multiplicação de minhocas e produção de mudas de tomate e alface. Acta Zoológica Mexicana, v.2, p.333-343, 2010.

Teixeira, I. R.; Mota, J. H.; Silva, A. G. Consórcio de hortaliças. Semina: Ciências Agrárias, v.26, p.507-514, 2005.
Tolentino Júnior, C. F.; Zárate, N. A. H.; Vieira, M. C. Produção da mandioquinha-salsa consorciada com alface e Beterraba. Acta Scientiarum. Agronomy, v.24, p.1447-1454, 2002.

Vidigal, S. M.; Pereira, P. R. G; Pedrosa, M. W. In: Paula Júnior T. J.; Venzon, M. (ed.). 101 culturas: Manual de tecnologias agrícolas. Belo Horizonte: EPAMIG, 2007. p.665-674. 